\title{
Evaluation of reproductive health status among women referring to rural healthcare centers in Neyshabur (Iran) in 2017
}

\author{
Khosheh Khaleghinezhad ${ }^{1}$, Nourossadat Kariman², Fatemeh Nahidi², Abbas Ebadi ${ }^{3}$, Malihe Nasiri ${ }^{4}$
}

${ }^{1}$ Ph.D. Student in Reproductive Health, Student Research Committee, Department of Midwifery and Reproductive Health, Shahid Beheshti University of Medical Sciences, Tehran, Iran

2 Assistant Professor, Midwifery and Reproductive Health Research Center, Department of Midwifery and Reproductive Health, Shahid Beheshti University of Medical Sciences, Tehran, Iran

${ }^{3}$ Professor, Behavioral Sciences Research Center, Life Style Institute, Nursing Faculty, Baqiyatallah University of Medical Sciences, Tehran, Iran

${ }^{4}$ Assistant Professor, Department of Biostatics, Faculty of Nursing and Midwifery, Shahid Beheshti University of Medical Sciences, Tehran, Iran

Type of article: Original

\begin{abstract}
Background: Reproductive health is one of the most important aspects of life. Moreover, rural women constitute the largest demographic in society who are deprived of health services.

Objective: To determine the reproductive health needs of rural women of reproductive age.

Methods: This cross-sectional study was conducted on 405 rural women referring to the rural healthcare centers of Neyshabur, Iran, in 2017. The study population was selected through random multistage sampling technique. Data collection was carried out using a standardized questionnaire, evaluating sexual and reproductive health needs. Data analysis was performed using descriptive statistics in SPSS version 17.

Results: According to the results, $99.2 \%$ and $95.5 \%$ of the females received prenatal and postpartum healthcare, respectively. In addition, the rate of cesarean section was $30.25 \%$ among the rural women. The contraceptive pill was the most known birth control method $(88.9 \%)$, whereas coitus interruptus was the most frequently used method (28.5\%). Moreover, $59.8 \%$ of the rural women married at the age of $\leq 18$ years. The most known sexually transmitted disease for these women was HIV/AIDS (81.7\%), and just more than half of them had a history of colored vaginal discharge over the past 12 months (56.8\%). Furthermore, these women reported $33.1 \%$ domestic violence over the past year.

Conclusion: The findings of the present study revealed the urgent need for planning programs to improve the reproductive health of rural women.
\end{abstract}

Keywords: Reproductive health, Sexual health, Women's health, Rural population

\section{Introduction}

The high importance of reproductive health in human societies has been globally recognized as part of human rights under the name of reproductive rights (1). Women's health directly affects the long-term programs of development in each country (2). Rural women constitute about one-third of the female population (37 million) in Iran (3). These females experience various aspects of discrimination and deprivation (4). Furthermore, according to the millennium development goals, rural women have improper conditions, compared to rural men and urban men and women (5). Regarding this, it is essential to accurately determine the unsatisfied health needs of these women to eliminate the shortages, and plan for better reproductive health services (6). Studies have indicated the low level of reproductive health in rural women compared to that in urban females (1). In this regard, among all maternal deaths occurring in

\section{Corresponding author:}

Assistant Professor Dr. Nourossadat Kariman, Midwifery and Reproductive Health Research Center, Department of Midwifery and Reproductive Health, School of Nursing and Midwifery, Shahid Beheshti University of Medical Sciences, Tehran, Iran. Tel.: +982188202517, Fax:+982188202517, Email: n_kariman@sbmu.ac.ir

Received: October 05, 2017, Accepted: January 20, 2018, Published: April 2018

iThenticate screening: January 12, 2018, English editing: February 23, 2018, Quality control: March 15, 2018

This article has been reviewed / commented by seven experts

(C) 2018 The Authors. This is an open access article under the terms of the Creative Commons Attribution-NonCommercialNoDerivs License, which permits use and distribution in any medium, provided the original work is properly cited, the use is non-commercial and no modifications or adaptations are made. 
Hormozgan province between 2005 and 2011, rural areas had the highest mortality rate (60.4\%) (7). Another important issue in reproductive health is the coverage of family planning methods. Unwanted pregnancy is regarded as an important general health problem due to its adverse outcomes for maternal and fetal health (8). According to statistics, the prevalence of unwanted pregnancy has been estimated as $30.6 \%$ in Iran (9). However, in a study conducted by Zamani, $42 \%$ of the rural women in Najafabad town experienced unwanted pregnancy (10), which is a sign of the widespread occurrence of this problem in rural women. Moreover, Zare affirmed that adolescent girls living in rural areas have a higher marriage and childbearing rate, compared to those in urban regions (11). Early marriage, lack of knowledge and information about sexual and reproductive health have led to increase in the vulnerability to HIV and other sexual and reproductive health risks (12). All of the mentioned issues create the underlying foundations for reproductive health risks in rural women. However, there are limited studies investigating the various dimensions of sexual and reproductive health in rural women. Villages are the most deprived regions in terms of health and hygiene. Therefore, it is fair to pay more attention to these areas, especially the vulnerable group of rural women. With this background in mind, the present study aimed to determine the reproductive health needs of rural women at fertility age in order to provide an opportunity for designing effective programs targeted toward the improvement of reproductive health among this population.

\section{Material and Methods}

\subsection{Study population}

This descriptive, cross-sectional study was conducted on rural women, who referred to the rural healthcare centers of Neyshabur, Khorasan Razavi, Iran, from January to April 2017. The sample size was determined as 405 cases considering type I error 0.05 , proportion 0.5 , degree of confidence $0.05 \%$, and $5 \%$ sample loss.

\subsection{Sampling area and study design}

Khorasan Razavi is the second populous province in Iran. Neyshabur is the second largest city in Khorasan Razavi province after Mashhad (provincial capital) (3). Neyshabur consists of four parts, each of which was regarded as a cluster. A list was provided from the villages of each cluster, and some villages were randomly selected through simple random sampling method in proportion to the covered villages. A total of 36 villages were randomly selected from four districts, including Central District 16, Zebarkhan District 9, Mianjolgeh District 6, and Sarvelaiat District 5. Subsequently, purposive sampling technique was carried out in each of the selected villages. The questionnaires were filled out by the researcher through interviews implemented in a calm and private environment at the rural healthcare center.

\subsection{Selection criteria}

\subsubsection{Inclusion criteria}

The inclusion criteria were: 1) age between 15 and 45 years, 2) married status and living with husband, 3) permanent residence in the village (more than one year), and 4) lack of any known physical or psychological illnesses.

\subsubsection{Exclusion criteria}

The exclusion criteria included the unwillingness of the participants to continue the interview.

\subsection{Data collection}

The data were collected using the Sexual and Reproductive Health Needs Assessment Questionnaire, which was designed by New Dimension Consulting for the International Organization for Migration and the United Nations Population Fund to be used among the mobile and vulnerable populations in Zimbabwe (13). This instrument consists of seven sections, including background information, safe motherhood, family planning, sexual behaviors, sexually transmitted infections, HIV/AIDS, as well as physical and sexual violence. The validity and reliability of the mentioned questionnaire was confirmed in Iran by Khani in 2015. The English questionnaire was translated into Persian through decentered or symmetric translation method. The process of cultural and social considerations and adaptation was supervised by the researcher throughout all phases of the study. The content validity index was higher than 0.8 for all items. In addition, the face validity (qualitative and quantitative), content validity (qualitative and quantitative), and reliability of the questionnaire have been approved (14). In this study, the reliability of the questionnaire was assessed using the test-retest method. A total of 40 women completed the questionnaire twice in 2-week intervals. The intra-class correlation coefficient (ICC) values were $\geq 0.87$.

\subsection{Ethical considerations}

The present study was approved by the Ethics Committee of Shahid Beheshti University of Medical Sciences (code: IR.SBMU.RETECH.REC.1395.588). Informed consent was obtained from all participants. In addition, all subjects were assured of the confidentiality of their personal information. 
http://www.ephysician.ir

\subsection{Statistical analysis}

Data analysis was performed using descriptive tests in SPSS, version 17 (IBM@ Corp., Armonk, NY, USA).

\section{Results}

According to the results, the mean ages of the females and their spouses were $30.99 \pm 6.55$ and $35.60 \pm 6.72$ years, respectively. In terms of the education level, $179(44.2 \%)$ subjects and $147(36.3 \%)$ spouses had elementary education or lower. In total, $242(59.8 \%)$ women and $294(72.4 \%)$ of their spouses were aged $\leq 18$ and $\leq 24$ years, respectively. Moreover, 340 (84.0\%) subjects were housewives, while 305 (75.3\%) spouses were simple workers, farmers, or animal husbandries. The mean length of marriage was $12.99 \pm 6.63$ years among the subjects. The evaluation of decision-making in families indicated that the husband was the head of the family in 383 (94.6\%) cases. Furthermore, purchase of home supplies was carried out by the husband in $312(77.0 \%)$ cases. Decisionmaking about receiving medical care and issues related to sexual and reproductive health were carried out by 272 $(67.2 \%)$ and $187(46.2 \%)$ women, respectively. The history of pregnancy, childbirth, postpartum, breastfeeding and unwanted pregnancy is presented in Table 1.

Table 1. Evaluation of participants in terms of the history of pregnancy, childbirth, postpartum, breastfeeding, and unwanted pregnancy

\begin{tabular}{|c|c|c|c|c|}
\hline \multicolumn{3}{|l|}{ Variables } & \multicolumn{2}{|c|}{$\begin{array}{l}\text { Mean (SD) / } \\
\mathrm{n}(\%)\end{array}$} \\
\hline & \multicolumn{2}{|l|}{ Number of pregnancies; Mean (SD) } & 2.3 & 1.3 \\
\hline & \multicolumn{2}{|l|}{ Age at the first pregnancy (years); Mean (SD) } & 20.8 & 3.7 \\
\hline & \multicolumn{2}{|l|}{ Number of prenatal cares; Mean (SD) } & 7.1 & 3.0 \\
\hline & \multicolumn{2}{|c|}{ Duration of the first prenatal care (months); Mean (SD) } & 1.8 & 0.8 \\
\hline & \multicolumn{2}{|l|}{ Visit for obtaining prenatal care; $\mathrm{n}(\%)$} & 371 & 99.2 \\
\hline & \multirow{2}{*}{$\begin{array}{l}\text { The most common risk factors for pregnancy } \\
\text { from the women's perspective; } \mathrm{n}(\%)\end{array}$} & Uterine bleeding & 295 & 72.8 \\
\hline & & Severe abdominal pain & 245 & 60.5 \\
\hline & \multirow[t]{4}{*}{ Provider of prenatal care services; $\mathrm{n}(\%)$} & Behvarz & 277 & 74.7 \\
\hline & & Midwife & 82 & 22.1 \\
\hline & & Physician & 10 & 2.7 \\
\hline & & Others & 2 & 0.5 \\
\hline & \multirow[t]{4}{*}{$\begin{array}{l}\text { The most common cause of not receiving } \\
\text { prenatal care; } n(\%)\end{array}$} & $\begin{array}{l}\text { Lack of adequate knowledge about services } \\
\text { provided at healthcare centers }\end{array}$ & 2 & 40 \\
\hline & & Inability to pay the healthcare expenses & 1 & 20 \\
\hline & & Excessive distance to health center & 1 & 20 \\
\hline & & Personal unwillingness & 1 & 20 \\
\hline & \multicolumn{2}{|c|}{ Complete tetanus vaccine status in the previous pregnancy; $\mathrm{n}(\%)$} & 326 & 87.9 \\
\hline & \multicolumn{2}{|c|}{ Complete status of receiving supplements status in the previous pregnancy; $\mathrm{n}(\%)$} & 276 & 74.4 \\
\hline & \multicolumn{2}{|c|}{ A history of problems during pregnancy, childbirth, and postpartum; $\mathrm{n}(\%)$} & 138 & 36.9 \\
\hline & $\begin{array}{l}\text { The most common problem occurring during } \\
\text { pregnancy and childbirth; } \mathrm{n}(\%)\end{array}$ & History of bleeding during the first trimester & 39 & 28.5 \\
\hline & \multicolumn{2}{|c|}{ Knowing 5 signs of risk symptoms during pregnancy; n (\%) } & 99 & 24.4 \\
\hline \multirow{3}{*}{$\begin{array}{l}\text { History of delivery; } \\
\mathrm{n}(\%)\end{array}$} & \multicolumn{2}{|l|}{ Last delivery in a clean environment } & 355 & 99.7 \\
\hline & \multicolumn{2}{|c|}{ Performing the delivery process by a trained individual } & 355 & 99.7 \\
\hline & \multicolumn{2}{|c|}{ C-section to total number of pregnancies ratio } & 229 & 30.25 \\
\hline \multirow{5}{*}{$\begin{array}{l}\text { History of } \\
\text { Postpartum; n (\%) }\end{array}$} & \multicolumn{2}{|l|}{ Receiving at least one postpartum care } & 338 & 95.5 \\
\hline & \multirow[t]{4}{*}{$\begin{array}{l}\text { The most common causes of not receiving } \\
\text { postpartum care }\end{array}$} & $\begin{array}{l}\text { Inadequate knowledge about services } \\
\text { provided at healthcare centers }\end{array}$ & 4 & 23.5 \\
\hline & & Inability to pay the healthcare expenses & 3 & 17.6 \\
\hline & & Excessive distance to health center & 2 & 11.8 \\
\hline & & Lack of public transportation & 2 & 11.8 \\
\hline \multirow{5}{*}{$\begin{array}{l}\text { History of } \\
\text { breastfeeding; n (\%) }\end{array}$} & \multicolumn{2}{|c|}{ Exclusive breastfeeding in the first six months of birth } & 323 & 91.8 \\
\hline & \multirow{4}{*}{$\begin{array}{l}\text { The most common causes of non-exclusive } \\
\text { breastfeeding in the first six months of birth }\end{array}$} & Causes related to maternal health & 6 & 17.6 \\
\hline & & Causes related to neonatal care & 6 & 17.6 \\
\hline & & Lack of belief in the adequacy of breast milk & 4 & 11.8 \\
\hline & & $\begin{array}{l}\text { Others (e.g., busy mother, having twins, and } \\
\text { lack of personal interest) }\end{array}$ & 18 & 52.9 \\
\hline
\end{tabular}


Table 2. Evaluation of the participants in terms of family planning and unwanted pregnancy

\begin{tabular}{|c|c|c|c|c|}
\hline \multicolumn{3}{|l|}{ Variables } & $\mathrm{n}$ & $\%$ \\
\hline \multirow{11}{*}{ Family planning } & \multirow[t]{3}{*}{ The most known contraceptive method } & Contraceptive pills & 360 & 88.9 \\
\hline & & Condom & 353 & 87.2 \\
\hline & & Contraceptive injections & 325 & 80.2 \\
\hline & \multirow[t]{2}{*}{ The most commonly applied method } & Condom & 216 & 53.3 \\
\hline & & Contraceptive pills & 185 & 45.7 \\
\hline & \multirow[t]{3}{*}{ The most preferred method } & Condom & 92 & 22.7 \\
\hline & & Intrauterine device & 82 & 20.2 \\
\hline & & Contraceptive pills & 75 & 18.5 \\
\hline & \multicolumn{2}{|l|}{ Current non-use of contraceptive methods } & 79 & 19.5 \\
\hline & \multirow[t]{2}{*}{ The most commonly applied method currently } & Coitus Interruptus & 93 & 28.5 \\
\hline & & Condom & 85 & 26.1 \\
\hline \multirow{6}{*}{$\begin{array}{l}\text { Unwanted } \\
\text { pregnancy }\end{array}$} & \multicolumn{2}{|l|}{ History of unwanted pregnancy in individuals } & 109 & 26.9 \\
\hline & \multicolumn{2}{|c|}{ History of using pregnancy termination methods by the individual } & 20 & 18.3 \\
\hline & \multicolumn{2}{|l|}{ History of using contraceptives before unwanted pregnancy } & 90 & 82.6 \\
\hline & \multirow{3}{*}{$\begin{array}{l}\text { The most common type of contraceptives used before } \\
\text { unwanted pregnancy }\end{array}$} & Coitus interruptus & 41 & 45.6 \\
\hline & & Contraceptive pills & 20 & 22.2 \\
\hline & & Condom & 17 & 18.9 \\
\hline
\end{tabular}

Table 3. Evaluation of the participants in terms of women's knowledge, sexual performance, and self-report of the history of sexually transmitted diseases in the females and their spouses

\begin{tabular}{|c|c|c|c|c|}
\hline \multicolumn{3}{|l|}{ Variables } & $\mathrm{n}$ & $\%$ \\
\hline \multirow{14}{*}{$\begin{array}{l}\text { Knowledge of } \\
\text { sexually } \\
\text { transmitted } \\
\text { diseases }\end{array}$} & \multirow{3}{*}{$\begin{array}{l}\text { The most known sexually transmitted } \\
\text { diseases }\end{array}$} & HIV/AIDS & 331 & 81.7 \\
\hline & & Candida (fungus) & 197 & 48.6 \\
\hline & & Hepatitis & 163 & 40.2 \\
\hline & \multirow[t]{3}{*}{ Symptoms of sexually transmitted diseases } & Discharges with an unpleasant odor & 296 & 73.1 \\
\hline & & Genital itching & 293 & 72.3 \\
\hline & & Lower abdominal pain & 285 & 70.4 \\
\hline & \multirow{3}{*}{$\begin{array}{l}\text { The most well-known routes of HIV/AIDS } \\
\text { transmission from the perspective of } \\
\text { participants }\end{array}$} & Vaginal sexual intercourse & 338 & 83.5 \\
\hline & & Reuse of syringe and needle & 307 & 75.8 \\
\hline & & Blood transfusion & 271 & 66.9 \\
\hline & \multirow{2}{*}{$\begin{array}{l}\text { The most unknown routes of HIV/AIDS } \\
\text { transmission from the perspective of } \\
\text { participants }\end{array}$} & Breastfeeding & 98 & 24.2 \\
\hline & & Oral sex & 98 & 24.2 \\
\hline & \multicolumn{2}{|c|}{$\begin{array}{l}\text { Believing that it is extremely rare or unlikely to be diagnosed with AIDS in the next } \\
\text { year }\end{array}$} & 229 & 56.5 \\
\hline & \multicolumn{2}{|l|}{ History of AIDS testing in the past year } & 4 & 1 \\
\hline & \multicolumn{2}{|c|}{$\begin{array}{l}\text { Lack of information about the possibility of being infected with HIV/AIDS even with } \\
\text { healthy appearance }\end{array}$} & 152 & 37.5 \\
\hline \multirow{8}{*}{$\begin{array}{l}\text { History of sexually } \\
\text { transmitted } \\
\text { diseases }\end{array}$} & \multirow{2}{*}{\multicolumn{2}{|c|}{$\begin{array}{l}\text { History of colored or unclear vaginal discharges during the past } 12 \text { months in women } \\
\text { History of vaginal wound during the past } 12 \text { months in women }\end{array}$}} & 230 & 56.8 \\
\hline & & & 43 & 10.6 \\
\hline & \multicolumn{2}{|c|}{ Searching for treatment of discharge or ulcer in genital area } & 198 & 84.3 \\
\hline & \multirow{3}{*}{$\begin{array}{l}\text { The most common causes of non-referral } \\
\text { for the treatment of sexually transmitted } \\
\text { diseases }\end{array}$} & Lack of personal interest & 24 & 57.1 \\
\hline & & Shame & 5 & 11.9 \\
\hline & & Improperness of the previous treatment & 4 & 9.5 \\
\hline & \multicolumn{2}{|c|}{ History of genital wounds in the spouse or sex partner over the past 12 months } & 20 & 4.9 \\
\hline & \multicolumn{2}{|l|}{ Searching for treatment by spouse or sex partner } & 10 & 50 \\
\hline \multirow{3}{*}{$\begin{array}{l}\text { Sexual } \\
\text { performance; } \\
\text { Mean (SD) }\end{array}$} & \multicolumn{2}{|c|}{ Having several sex partners by the spouses of women } & 24 & 5.9 \\
\hline & \multirow{2}{*}{\multicolumn{2}{|c|}{$\begin{array}{l}\text { Start having sex at the age of } \leq 15 \text { years } \\
\text { Mean age at the onset of sexual relations } i\end{array}$}} & 68 & 16.8 \\
\hline & & & 18.9 & 3.7 \\
\hline
\end{tabular}

The data related to family planning and unwanted pregnancy are reported in Table 2. Data related to sexually transmitted diseases, women's knowledge, sexual performance, and history of sexually transmitted diseases in females or their spouses is illustrated in Table 3 . The most common cause of non-use of family planning techniques was current pregnancy or tendency toward pregnancy $(\mathrm{n}=66,83.5 \%)$. In total, $303(93.0 \%)$ participants learned 
about family planning methods in healthcare centers. Regarding physical and sexual violence, 134 (33.1\%) women experienced physical violence in the past year, which were mainly husband-to-wife cases $(\mathrm{n}=126,94.0 \%)$. In more than half of the cases, the women discussed this issue with no one $(n=68,50.7 \%)$, the main cause of which was fear of bad reputation $(n=32,47.1 \%)$, creation of problems in their relationships $(n=27,39.7 \%)$, and uselessness of reporting or talking about domestic violence $(n=23,33.8 \%)$. The best strategies to avoid domestic violence against the women were reported to be educational programs for females $(\mathrm{n}=230,56.8 \%)$, educational programs for males $(\mathrm{n}=216,53.3 \%)$, psychological counseling $(\mathrm{n}=208,51.4 \%)$, and religious counseling $(\mathrm{n}=128,31.6 \%)$. Sexual violence was reported by $285(70.4 \%)$ cases, which was mainly $(\mathrm{n}=283,99.3 \%)$ imposed by the husband. Nevertheless, the subjects talked with no one about this issue in the majority of cases $(n=219,76.8 \%)$, which was mainly due to embarrassment and the commonness of this issue as reported by $133(60.7 \%)$ and $66(30.2 \%)$ females, respectively. The best solutions for the prevention of domestic violence against these women were proposed to be the administration of educational programs for females $(n=259,64.0 \%)$, female's avoidance from going to insecure places $(\mathrm{n}=222,54.8 \%)$, psychological counseling $(\mathrm{n}=189,46.7 \%)$, and implementation of educational programs for males $(\mathrm{n}=172,42.5 \%)$.

\section{Discussion}

The present study aimed to evaluate various dimensions associated with reproductive health in rural women. These dimensions included safe maternity, family planning, sexual performance, sexually transmitted diseases, HIV/AIDS, as well as physical and sexual violence. According to the results, only a quarter of the women knew about at least five signs of prenatal risk. The majority of the subjects reported uterine bleeding and severe abdominal pain as the symptoms signifying a pregnancy risk. In a study conducted by Kabakyenga et al. (2011), 52\%, 72\%, and 72\% of females were familiar with at least one major risk factor for pregnancy, childbirth, and postpartum periods, respectively. Only $19 \%$ of the participants knew about three or more risk factors for the mentioned periods. In this regard, minimum knowledge about one risk factor for pregnancy or childbirth had a statistically significant relationship with birth preparation (15). Therefore, the lack of information about pregnancy risk factors can be indicative of the women's unfavorable knowledge level about this domain. Based on the definitions, a minimum of six cases of prenatal care is regarded as adequate for a low risk pregnancy (16). Although $99.2 \%$ of the rural women received prenatal care, $29.1 \%$ of them had not received such care adequately. On the other hand, the quality and quantity of prenatal care in rural areas is more favorable than that in urban areas (16), which is mainly due to the presence of local health workers in these regions. Furthermore, the results were indicative of the acceptable rate of postpartum care. However, the high level of non-exclusive breastfeeding is indicative of the need for the provision of more education and facilities for more active women. The evaluation of the total childbirth status revealed the high prevalence of C-section among the rural women (30.25\%), which is above the global standard (17). The rate of this procedure can be reduced by preventing unnecessary C-section (e.g., elective C-section). Khsravi et al. (2006) demonstrated a statistical relationship between the type of pregnancy and place of residence. In this regard, the urban mothers underwent $\mathrm{C}$-section twice as much as the rural mothers $(\mathrm{OR}=2.22)(18)$. Moreover, the general health policies designed to promote natural delivery over the past few years has led to the reduction of C-section rate (19). Contraceptive pills and condoms were the most recognized birth control methods, and coitus interruptus and condom were the most applied methods by the rural women. However, knowledge and use of emergency contraceptive methods were at a significantly low level. In a study performed by Zanjani and Jazayeri (2014), the reproductive health showed a positive correlation with the level of knowledge about contraceptive methods after marriage, participation rate in family decision-making, and accessibility to contraceptives (1). Moreover, Sadri et al. (2011) asserted that the knowledge of the women, covered by family planning services, about complications, care, and follow-up of the contraceptives was not favorable (20). The results of this study were also indicative of the undesirable level of knowledge in the family planning domain. While the mean age of initiating sexual relations was 18.9 years and $16.8 \%$ of these women reported this age as 15 years and less.

Early marriage can lead to the elevation of unfavorable complications during pregnancy and childbirth. Adolescent females are at higher risk of violence and have lower involvement in making decisions about their reproductive health. Moreover, they are sometimes not allowed to receive healthcare treatment (21). These factors are indicative of the need of rural societies for effective measures in this regard. The rural women had limited knowledge about sexually transmitted diseases. Moreover, more than half of these women had a history of colored vaginal discharge. In addition, one fifth of these individuals did not refer to the healthcare centers to receive therapeutic interventions. These findings indicated the high incidence of sexually transmitted infections among rural women. Although Margdarinejhad (2014) demonstrated that the place of residence had no significant association with candida and trichomonas infections (23), more information is needed in this area. After the evaluation of rural women's 
knowledge about AIDS, only $57 \%$ of the women were familiar with more than half of the AIDS transmission routes. Additionally, $37.5 \%$ of these women selected the alternatives of "no" or "I do not know" when answering the question of "Can a person with normal appearance have AIDS?". In a study conducted by Ashrafinia et al. (2014), the majority of the women were reported to have medium knowledge $(55.2 \%)$ and positive attitude toward transmission routes and prevention of AIDS (95.8\%) (25). This finding is consistent with those of our study, which was indicative of the need for more education in this area. On the other hand, physical and sexual violence was at a high level among rural women. In a study conducted by Sapkota et al. (2016), according to the participants' selfreport, the prevalence rates of physical violence were $29.6 \%$ and $15.2 \%$ during lifetime and in the past year, respectively (26). Moreover, Ali Kamali et al. (2015) demonstrated a significant difference between urban and rural pregnant women in terms of physical, mental, and sexual violence (27). Accordingly, they revealed that the rural women were exposed to more physical, psychological, and sexual violence. In the present study, domestic violence had a higher prevalence in the rural women than that in the urban females. This higher level of violence in rural areas is mainly due to women's deprivations of some services and such risk factors as low education level, limited accessibility to sufficient financial resources, and communication limitations. Therefore, the reduction of these impacts must be prioritized. The limitations of this study included the implementation of sampling only in the rural healthcare centers. Furthermore, we did not use additional diagnostic tests. The strength of this study was the investigation of a topic in rural women that has been less studied in Iran.

\section{Conclusions}

The findings of this study indicated the need for planning the programs targeted toward the improvement of sexual and reproductive health among rural women. Further studies are recommended to investigate the needs of sexual and reproductive health in rural women in several provinces using a larger sample size and complementary diagnostic tests.

\section{Acknowledgments:}

This article was derived from a dissertation submitted in partial fulfillment of the requirements for a Ph.D. degree on reproductive health. The present study was approved by the International Branch of Shahid Beheshti University of Medical Sciences, Tehran, Iran. Hereby, we extend our gratitude to the Research Deputy of the university, healthcare network of Neyshabur, all healthcare professionals in rural healthcare centers, and participants for their cooperation in this study.

\section{Conflict of Interest:}

There is no conflict of interest to be declared.

\section{Authors' contributions:}

All authors contributed to this project and article equally. All authors read and approved the final manuscript.

\section{References:}

1) Zanjani H, Jazaeri A. A comparative study of factors affecting the reproductive health of women living Dorud and Kouhdasht city of Lorestan province. JIUMS. 2015; 22(6): 103-14.

2) Lopez-Claros A, Zahidi S, editors. Women's empowerment: measuring the global gender gap. World Economic Forum. Geneva; 2005.

3) Iran Statistical Center. The Findings of Iran's Census of Peoples and Housing 2011 Tehran: Iran Statistical Center; 2012. Available from: https://www.amar.org.ir/Portals/1/Iran/90.pdf.

4) Moshiri S, Mahdavi M, Oliaei M. The role of literacy and women work force in rural household income, case study: Divandareh rural women, Kurdistan, Iran. Joghrafia-va Tow se'eh. 2009; 14: 69-82. doi: 10.22111/GDIJ.2009.1217.

5) Women Watch. Facts \& Figures: Rural Women and the Millennium Development Goals. 2011. Available from: http://www.un.org/womenwatch/feature/ruralwomen/facts-figures.html.

6) WHO. Defining sexual health. Report of a technical consultation on sexual health. Geneva; 2002.

7) Rajai M, Zare B, Dadpour S, Fallahi s, Rajai F, Pourahmad Gourbandi F, et al. Determining the Frequency and Causes of Maternal Mortality in Hormozgan Province, Iran during 2005-2011. IJOGI. 2014; 16(87): 914. doi: 10.22038/IJOGI.2014.2432.

8) Finer L, Zolna M. Declines in Unintended Pregnancy in the United States, 2008-2011. N Engl J Med. 2016; 374(9): 843-52. doi: 10.1056/NEJMsa1506575. 
9) Moosazadeh M, Nekoei-Moghadam M, Emrani Z, Amiresmaili M. Prevalence of unwanted pregnancy in Iran: a systematic review and meta-analysis. Int J Health Plann Manage. 2014; 29(3): 277-90. doi: 10.1002/hpm.2184.

10) Zamani F, Bashardoost N, Rajabi Z. Unwanted Pregnancy in Rural Women of Najafabad. Fayz. 2005; 9(1): 56- 61.

11) Zare A. The study spatial patterns of prevalence among marriage women less than 20 year and childbearing them Shiraz university; 2013.

12) Santhya KG, Jejeebhoy SJ, Ghosh S. Early marriage and sexual and reproductive health risks: experiences of young women and men in Andhra Pradesh and Madhya Pradesh, India. Population Council. 2008: 32-51.

13) UNFPA. Sexual and reproductive health (SRH) needs assessment among mobile and vulnerable population (MVP) communities in Zimbabwe. Study report. Zimbabwe: New Dimension Consulting Ltd; 2008.

14) Khani S, Moghaddam-Banaem L, Mohamadi E, Vedadhir AA, Hajizadeh E. Psychometric properties of the Persian version of the Sexual and Reproductive Health Needs Assessment Questionnaire. EMHJ. 2015; 21(1): 29-38. doi: 10.26719/2015.21.1.29.

15) Kabakyenga J, Östergren P, Turyakira E, Pettersson K. Knowledge of obstetric danger signs and birth preparedness practices among women in rural Uganda. Reprod Health. 2011; 8(33). doi: 10.1186/17424755-8-33.

16) Zahedi R, Rahmanian S, Kohpeima Jahromi V. Assessment the Quantity and Quality of Prenatal Care referred to Maternity and Obstetrics' Facility. hbrj. 2016; 1(3): 199-213.

17) Gibbons L, Belizan J, Lauer J, Betran A, Merialdi M, Althabe F. The global numbers and costs of additionally needed and unnecessary caesarean sections performed per year: overuse as a barrier to universal coverage. World Health Report; 2010. Available from: https://pdfs.semanticscholar.org/b45d/0962892adccb873f7e2b8131b0c934fef77e.pdf.

18) Khsravi M, Armat M, Jarolahi N. Prevalence of Cesarean section and its related factors. J Holist Nurs Midwifery. 2006; 16(1): 12-7.

19) Piroozi B, Moradi G, Esmail Nasab N, Ghasri H, Farshadi S, Farhadifar F. Evaluating the effect of health sector evolution plan on cesarean rate and the average costs paid by mothers: A case study in Kurdistan province between 2013-2015. Hayat. 2016; 22(3): 245-54.

20) Sadri GH, Ghaed Sharafi B, Farajzadegan Z. Do Reproductive Women Have Awareness about Complications of Birth Control Methods and the Required Follow-up? Journal of Isfahan Medical School. 2011; 29(158): 1616-29.

21) Lotfi R. Health consequences of early marriage in women. Journal of Women and Health. 2010; $2: 67-79$.

22) Regmi P, van Teijlingen E, Simkhada P, Acharya D. Barriers to Sexual Health Services for Young People in Nepal. J Health Popul Nutr. 2010; 28(6): 619-27. doi: 10.3329/jhpn.v28i6.6611. PMID: 21261208, PMCID: PMC2995031.

23) Margdari Nezhad M, Mahasti Jouybari L, Sanagoo A, Haghdust Z, Mobasheri E. Prevalence of Cervicovaginal Infections in Relationship with Some Factors In Pap Smear Sampling. IJOGI. 2014; 17(110): 1621. doi: 10.22038/IJOGI.2014.3251.

24) Nasirian M, Karamouzian M, Kamali K, Nabipour A, Maghsoodi A, Nikaeen R, et al. Care seeking patterns of STIs-associated symptoms in Iran: findings of a population-based survey. Int J Health Policy Manag. 2016; 5(1): 5-11. doi: 10.15171/ijhpm.2015.146.

25) Ashrafinia F, Janani L, Khajeh Kazemi R, Dastoorpour M. The Relationship between fear of AIDS with childbearing age women knowledge and attitude toward AIDS. RJMS. 2014; 20(117): 76-84.

26) Sapkota D, Bhattarai S, Baral D, Pokharel PK. Domestic violence and its associated factors among married women of a village development committee of rural Nepal. BMC Res Notes. 2016; 19(9): 178. doi: 10.1186/s13104-016-1986-6.

27) Ali Kamali M, Rahimi Kian F, Mir Mohammad Ali M, Mehran A, Shafie E. Comparison of domestic violence and its related factors in pregnant women in both urban and rural population in Zarand city, 2014. J Clin Nurs Midwifery. 2015; 4(2): 69-78. 